\title{
Acesso à informação, política digital e sustentabilidade ambiental no Brasil ${ }^{1}$
}

\section{Acess to information, digital politics and environmental susteinability in Brazil}

\author{
Danilo Rothberg \\ Coordenador do Programa de Pós-Graduação em Comunicação da Faculdade de Arquitetura, Artes e Comunicação da Unesp, \\ Bauru, SP, Brasil \\ ORCID: 0000-0002-3103-8154 \\ <danroth@uol.com>
}

\section{Como citar este artigo (How to cite this article):}

ROTHBERG, Danilo. Acesso à informação, política digital e sustentabilidade ambiental no Brasil. Revista Famecos, Porto Alegre, v. 25, n. 3, p. 1-19, setembro, outubro, novembro e dezembro de 2018: ID28376. DOI: http://dx.doi.org/10.15448/1980-3729.2018.3.28376.

\section{RESUMO}

Este artigo apresenta os resultados de pesquisa sobre a esfera da transparência proativa on-line das políticas de sustentabilidade ambiental no Brasil. Foram avaliadas as informações sobre políticas da área disponíveis em 284 páginas web dos portais de governo dos 26 Estados brasileiros, Distrito Federal e Ministério do Meio Ambiente por meio de análise de conteúdo orientada por categorias formuladas com apoio na literatura sobre avaliação de políticas públicas. A análise indica, como resultados, que os portais exibem de $14 \%$ a $47 \%$ das informações tidas como necessárias para a caracterização completa de uma política da área, conforme o contexto teórico-metodológico da pesquisa. A interpretação dos resultados sugere uma associação de fatores a ser explorada por estudos futuros: quanto mais desenvolvido for o agronegócio em nível macrorregional, maior será o desempenho da macrorregião na transparência online. A correspondência entre transparência de governo e desenvolvimento econômico tem sido explorada por vários estudos e é recolocada pelos resultados da presente pesquisa.

Palavras-chave: Direito à informação, Política Digital. Sustentabilidade

\section{ABSTRACT}

This paper presents the results of research on the field of proactive online transparency of environmental sustainability policies in Brazil. The available information on policies of that area on 284 web pages of the government portals of the 26 Brazilian states, the Federal District and the Ministry of the Environment was evaluated through content analysis formulated with support of the literature on public policy evaluation. The analysis indicates, as a result, that the web portals present from $14 \%$ to $47 \%$ of the information considered necessary for the complete characterization of a policy of the area, according to the theoretical-methodological context of the research. The interpretation of the results suggests an association of factors to be explored by future studies: the more agribusiness is developed at the macroregional level, the greater the performance of the macroregion in online transparency. The correspondence between government transparency and economic development has been explored by several studies and is brought by the results of the present research.

Keywords: Right to Information. Digital Politics. Sustainability

1 Pesquisa financiada pela Fapesp (Fundação de Amparo à Pesquisa do Estado de São Paulo, Processo 2013/22772-5). Versão inicial deste trabalho foi apresentada ao Grupo de Trabalho Comunicação e Política do XXVI Encontro Anual da Compós, Faculdade Cásper Líbero, São Paulo - SP, 06 a 09 de junho de 2017. 


\section{Introdução}

A política digital criou expectativas de facilitar as interações entre o poder público e a sociedade. No Brasil, têm sido notadas formas criativas de comunicação on-line entre atores que influenciam a governança ambiental em diversas regiões. A novidade pode significar a busca de estratégias pelo poder público para lidar com desafios subjacentes à influência do poder econômico sobre as decisões políticas que envolvem a área.

Como fonte de informação relevante sobre políticas públicas formuladas democraticamente para enfrentar os desafios da sustentabilidade, os portais web de governo e sua potencial contribuição para gerar transparência e accountability tornaram-se objeto de pesquisa que requer compreensão aprofundada e abrangente. De forma geral, a pesquisa científica tem avançado com a produção de conhecimento sobre características, armadilhas e insuficiências da exploração da internet para a expansão da política. Em particular no campo da comunicação, um dos focos tem sido a investigação sobre o atendimento do direito à informação por portais de governo que sustente formas de verificar o compromisso com o desenvolvimento sustentável exigidos da gestão pública pelos diversos atores sociais.

Este artigo apresenta resultados de pesquisa que identificou a potencial contribuição da informação política, reunida, organizada e disseminada por meio de práticas de democracia digital, sobre sustentabilidade ambiental para o fortalecimento da cidadania no Brasil, no que se refere ao exercício do direito à informação. Foi avaliada a qualidade de portais web de governo como fonte de informação sobre o desempenho das políticas estaduais e federais de sustentabilidade ambiental. A análise indica que os portais exibem de $14 \%$ a 47\% das informações tidas como necessárias para a caracterização completa de uma política da área, conforme o contexto teórico-metodológico da pesquisa. A interpretação dos resultados sugere uma associação de fatores que levanta uma hipótese a ser explorada por estudos futuros: quanto mais desenvolvido for o agronegócio em nível macrorregional, maior será o desempenho da macrorregião na transparência online, o que deve ser verificado à luz de estudos indicando uma associação positiva entre transparência de governo e desenvolvimento econômico, operada por meio da responsabilização do poder público que contribui para a ampliação da governança democrática.

No percurso aqui desenvolvido, em primeiro lugar são apresentadas teorizações fundamentais. Em segundo lugar, a metodologia de avaliação da comunicação de política ambiental, aplicada pela pesquisa, é caracterizada. Em terceiro lugar, os resultados são apresentados e discutidos. Conclusões sintetizam o percurso. 


\section{Teorizações fundamentais}

A fim de atender às demandas de informação, os portais web de governo precisam de concepção gerencial e de design que não são obtidos por meio de tarefas simples, uma vez que as decisões envolvidas vão além de considerações técnicas e administrativas. Tais decisões "são atos políticos que têm implicações importantes para a condução da administração pública e da democracia. Esses canais de comunicação podem alterar significativamente os processos e resultados democráticos", salientam Brewer, Neubauer \& Geiselhart (2006, p.473).

Embora a oferta oficial de informações não seja, obviamente, suficiente para explorar todo o potencial da democracia digital (Coleman \& Blumler, 2009), deve ser tomada como o primeiro passo de um processo que pode culminar em um uso mais amplo de tecnologias para mediar interesses diversos (Khan, 2015) e encontra-se teoricamente sustentada pela perspectiva deliberativa subjacente aos desenvolvimentos contemporâneos e realizações efetivas de democracia digital (Dahlberg, 2011).

A divulgação proativa on-line de informações sobre políticas públicas por governos é obrigatória de acordo com as leis de direito à informação existentes em mais de 90 países (Dokeniya, 2013). No entanto, estudos sugerem que "apesar da consistência crescente nos padrões de divulgação proativa contida nas leis nacionais de acesso à informação, as normas internacionais ainda não estão desenvolvidas significativamente" (Darbishire, 2010, p. 19).

Darbishire (2010) mapeia catorze classes de informações que podem ser consideradas como padrões ideais do que deve ser disseminado proativamente: 1. Informações institucionais; 2. Informações organizacionais; 3. Informações operacionais; 4. Decisões e atos; 5 . Informação dos serviços públicos; 6 . Informações sobre o orçamento; 7. Informações sobre reuniões abertas; 8. Tomada de decisão e participação pública; 9. Informações sobre subsídios; 10. Informação sobre contratos públicos; 11 . Listas, registos, bases de dados; 12. Informação sobre as informações detidas; 13. Informações sobre acesso a publicações oficiais; 14 . Informações sobre a existência do próprio direito à informação.

A Assembleia Geral da Organização dos Estados Americanos (OAS, 2012, p. 16) apresenta uma lista de 17 classes de informações de relevância permanente, incluindo "mecanismos de relatórios e monitoramento relevantes para a autoridade pública, incluindo seus planos estratégicos, códigos de governança e indicadores-chave de desempenho, incluindo quaisquer relatórios de auditoria".

De acordo com a legislação brasileira de acesso à informação (lei 12.527/2011, artigo 8), é "dever dos órgãos e entidades públicas promover, independentemente de requerimentos, a divulgação em local de fácil acesso, 
no âmbito de suas competências, de informações de interesse coletivo ou geral por eles produzidas ou custodiadas" (Brasil, 2011). Isto inclui "informações concernentes a procedimentos licitatórios, inclusive os respectivos editais e resultados, bem como a todos os contratos celebrados", "dados gerais para o acompanhamento de programas, ações, projetos e obras de órgãos e entidades" e "respostas a perguntas mais frequentes da sociedade". Além disso, "os órgãos e entidades públicas deverão utilizar todos os meios e instrumentos legítimos de que dispuserem, sendo obrigatória a divulgação em sítios oficiais da rede mundial de computadores (internet)". O decreto 7.724/2012, que regulamenta a lei 12.527/2011, ainda especifica em seu artigo 7 que deverão ser divulgados, nos portais web oficiais, "programas, projetos, ações, obras e atividades, com indicação da unidade responsável, principais metas e resultados e, quando existentes, indicadores de resultado e impacto" (Brasil, 2012).

No entanto, críticos argumentam que diretrizes, normas ou políticas que regulem efetivamente a transparência proativa devida sob a lei permanecem inexistentes; além disso, os obstáculos colocados por uma cultura política de sigilo podem dificultar o cumprimento da norma jurídica (Rothberg, Napolitano \& Resende, 2013; Batista, 2012; Damatta, 2011).

A literatura sobre avaliação de políticas permite a consideração de outras classes de informação, incluindo aspectos como condições sociais, econômicas, políticas e ambientais que conduzem a uma política; raciocínio subjacente a uma política; termos gerais de compromissos, números, estatísticas, projeções e calendários; recursos financeiros e humanos mobilizados; medidas de eficiência (gestão de políticas), eficácia (resultados reais) e eficácia (resultados em termos de transformação real de condições anteriores); resultados de pesquisas de satisfação dos cidadãos; e avaliação dos resultados em termos de justiça social e equidade na distribuição dos benefícios (Weiss, 1998; Henry, 2001; Arretche, 1998; Costa \& Castanhar, 2003).

A divulgação de informações sobre a implementação de políticas pode ser particularmente relevante em uma república constitucional federal como a brasileira, na qual os níveis de gestão pública de estados e municípios devem cumprir as leis e regulamentos nacionais, e na qual o sistema de gestão participativa de bacias hidrográficas, jurisdição relevante para a sustentabilidade ambiental, é realizado de acordo com a legislação estadual, mas deve estar em acordo com as políticas nacionais.

O atual sistema de gestão da água se caracteriza como estrutura política em que a disponibilidade de informações sobre a implementação de políticas tem sido estratégica, envolvendo sinergias entre os níveis de governo federal, estadual e municipal. Abers \& Keck (2013) sugerem que a integração dos níveis 
políticos pode ser tomada como um fator importante da reforma de gestão que ocorreu no Brasil após a redemocratização na década de 1980. “Com a proposta de integrar um conjunto diversificado de áreas políticas num único sistema, a reforma da gestão da água tornou-se uma arena na qual uma grande variedade de atores com diferentes posições (...) trabalhou para mudar a forma como as pessoas compreendiam e tomavam decisões sobre os recursos hídricos" (Abers \& Keck, 2013, p. 3).

A relação entre os três níveis de governo requer comunicação aberta e disponibilidade de informações completas e confiáveis sobre a implementação de políticas, como contribuição para o estabelecimento do que Abers \& Keck (2013, p. 3) chamam de "autoridade prática", entendida como um tipo de "poderem-prática gerado quando determinados atores (indivíduos ou organizações) desenvolvem capacidades e ganham reconhecimento dentro de uma área específica de políticas públicas, permitindo-lhes influenciar o comportamento de outros atores".

O sistema brasileiro de gestão da água é emblemático do tipo de política participativa que tornou tão importante para o governo cumprir as regras proativas de transparência que afetam a gestão pública em geral e particularmente a governança ambiental. "Ao longo de duas décadas, os ativistas da reforma da água negociaram com atores que defendem uma ampla gama de interesses para tentar desenvolver um novo projeto institucional", incluindo os conselhos participativos estaduais e federais como órgãos de tomada de decisão em nível de bacia hidrográfica, segundo a revisão de Abers \& Keck (2013, p. 5). Para que os acordos participativos brasileiros prosperem, a divulgação de informações que permitam à sociedade examinar as políticas públicas é fundamental para fortalecer a política democrática.

Ademais, aspolíticas degestão debaciashidrográficasederecursoshídricos, resíduos sólidos, biodiversidade, áreas protegidas, uso da terra e licenciamento ambiental estão sob crescente escrutínio no Brasil, colocando novas exigências de governança sobre a política democrática. A responsabilização (accountability), particularmente na sua dimensão vertical, impõe exigências de transparência extensivas aos representantes e servidores públicos (O’Donnel, 1998).

Mas cabe registrar que a divulgação proativa já era uma questão central para o avanço da política democrática de sustentabilidade muito antes de a legislação contemporânea de direito à informação ter apontado para a internet como seu canal principal. A Convenção de Aarhus, estabelecida pela Comissão Econômica das Nações Unidas para a Europa em 1998, assumiu a causa ao pressionar os governos democráticos e exigir deles a divulgação de informação necessária para que as pessoas compreendessem o que era considerado 
fundamental para sustentar a participação pública na tomada de decisão e acesso à justiça em matéria ambiental (Unece, 1998). O nível de detalhe então especificado já era elevado e incluía "informação que permita aos consumidores fazerem escolhas ambientais informadas" e "documentos de política, tais como documentos sobre estratégias, políticas, programas e planos de ação relacionados ao ambiente e relatórios de progresso gerados nos diversos níveis de governo" (artigo 5).

Em particular, a perspectiva do fortalecimento da política democrática situa a "importância de uma sociedade civil forte na obtenção de uma forma de responsabilização baseada no escrutínio público", de acordo com Bevir (2009, p. 28), que se refere ao ideal de uma sociedade aberta na qual cidadãos e setores sociais monitorem de perto o desempenho do governo (Bevir, 2010).

A pertinência da ampla disponibilidade de informação sobre políticas de sustentabilidade também pode ser vista sob a ótica da concepção de Latour (2004) de política da natureza, que reivindica a consolidação de uma visão da ecologia política segundo a qual a vida pública deve considerar a natureza não como um elemento isolado dominado pela lógica econômica de sua exploração por cadeias industriais, mas sim como uma elaboração humana filosófica.

Além disso, em uma sociedade de risco, a ciência não é mais um árbitro final sobre as consequências decorrentes de numerosos eventos aparentemente imprevisíveis que afetam o meio ambiente (Beck, 1992). Na sociedade de risco, a credibilidade do conhecimento científico se dissolve à medida que se revela incapaz de prever como gerenciar os efeitos de riscos que, afinal, passam a ser percebidos como absolutamente intrínsecos ao desenvolvimento. Desloca-se assim o papel da gestão da ciência e da tecnologia necessárias à sustentabilidade ambiental, que passam a escapar da autoridade dos cientistas, o que aumenta as expectativas depositadas sobre a política democrática como via plausível para um ambiente saudável. Isto é, a legitimidade dos tomadores de decisão em políticas de sustentabilidade começa a ser questionada se as decisões forem obtidas sem um exame público apropriado, o que, por sua vez, depende principalmente da ampla disponibilidade de informações.

\section{Metodologia de avaliação da comunicação de política ambiental}

Avaliamos as informações sobre políticas de sustentabilidade ambiental provenientes de todas as 284 páginas web dos portais oficiais de secretarias de meio ambiente dos 26 Estados brasileiros, Distrito Federal e Ministério do Meio Ambiente disponíveis no ano de 2014. Este período foi escolhido para coleta de dados porque nele se pode esperar, como ano de eleições para Presidência 
da República, Senado e Câmara Federal, Assembleias Legislativas e governos estaduais, mais visibilidade de mandatários e candidatos.

A amostra foi, assim, composta por 284 unidades de análise, considerandose todo o conteúdo textual - excluindo-se o conteúdo imagético e o conteúdo eventualmente disponível em hyperlinks para páginas externas - de cada página web, identificada por um único endereço www, como uma unidade de significado a ser classificada dentro das categorias previstas.

A análise de conteúdo foi realizada por meio de procedimento de classificação em 20 categorias distribuídas em seis eixos, formuladas com base em referenciais provenientes da literatura sobre avaliação de políticas públicas que indicam a variedade de aspectos decorrentes da escolha de uma linha de ação entre outras no âmbito da decisão pública (Weiss, 1998; Henry, 2001; Arretche, 1998; Costa \& Castanhar, 2003; Bellen, 2006; Trevisan \& Bellen, 2008). Para a elaboração da lista de categorias, também foram consideradas tanto a normatividade imposta pela legislação federal de acesso à informação no Brasil (lei 12.527/2011 e decreto 7.724/2012) quanto os diversos aspectos indicados pela literatura internacional sobre o assunto (Darbishire, 2010; OAS, 2012), que juntos fundamentaram a formulação da lista de 20 categorias, as quais tiveram suas condições de validade, homogeneidade e exaustividade verificadas e confirmadas em pré-testes, conforme as prescrições metodológicas da análise de conteúdo (Fonseca Junior, 2006; Krippendorff, 1980).

As categorias de análise foram estas:

Eixo 1: antecedentes e diagnósticos. Refere-se a contexto e diagnósticos sobre o cenário mais amplo que precede e conduz à criação e implementação de uma política específica, incluindo as seguintes categorias: 1. Contexto social: referem-se ao contexto social em que uma política opera, envolvendo fatores como moradia, trabalho, lazer, saúde etc; 2. Contexto econômico: refere-se ao âmbito em que uma política opera, envolvendo fatores como emprego, nível de atividade industrial, inovação etc. 3. Antecedentes políticos: acordos, acordos e alianças políticas que conduzam ou contribuem para a formulação, implementação e execução de uma política; 4. Nível de desenvolvimento científico e tecnológico: refere-se aos conhecimentos específicos que uma determinada política exige que sejam desenvolvidos, envolvendo fatores como

2 Esta metodologia foi inicialmente apresentada em ROTHBERG, D. Teoria e pesquisa da comunicação digital para sustentabilidade. In: XXIII Encontro da Compós - Associação Nacional dos Programas de Pós-Graduação em Comunicação, Belém (PA), 2014, p. 1-16, disponível em https://goo.gl/90X7a7, texto posteriormente publicado em versão revisada como ROTHBERG, D. Teoria e pesquisa da comunicação digital para sustentabilidade. In: LIMA, M. C.; ALMEIDA JÚNIOR, A.; ANDRADE, T. N. (orgs.). Comunicação, tecnologia e ambiente. Recipe, PE: Hucitec; Fundação de Amparo à Ciência e Tecnologia do Estado de Pernambuco, 2015, p. 125-143. 
financiamento público e laboratórios necessários; 5. Informações legais: leis, decretos, regulamentose regulamentossubjacentesàimplementação da política.

Eixo 2: propósitos. Inclui as seguintes categorias: 6 . Objetivos: constituem um cenário genérico a ser alcançado, não necessariamente quantitativamente caracterizado; 7. Metas: referem-se a resultados objetivamente esperados e prazos de implementação, em termos de estatísticas e projeções. 8. Recursos e critérios de eficiência: referem-se à relação entre os recursos mobilizados na implementação de uma política e os resultados obtidos, envolvendo planos de gestão, medidas de otimização, resultados de benchmarking etc. 9. Ações: atividades e projetos em curso para cumprir compromissos. 10. Informações operacionais, parcerias e convênios para o acesso aos benefícios: referemse a procedimentos implementados pelo setor público, incluindo vínculos estratégicos entre o poder público e instituições públicas e privadas para permitir acesso a serviços públicos, como formulários, instruções de registro etc.

Eixo 3: normas e padrões. Refere-se a critérios estabelecidos pelas agências governamentais dentro de um quadro regulatório, incluindo as seguintes categorias: 11. Prevenção de riscos: riscos ambientais a serem controlados na execução de uma determinada política; 12. Recursos de gestão: recursos humanos, materiais e financeiros investidos sob uma política.

Eixo 4: públicos e setores beneficiados. Refere-se a critérios utilizados para decidir por que certos recursos devem ser alocados em benefício de determinado grupo, classe social ou setor econômico, possivelmente em detrimento de outros, incluindo as seguintes categorias: 13. Público-alvo: estratos, grupos etários, setores empresariais, entidades, instituições etc.; 14. Instrumentos de relacionamento: refere-se a como um governo procurou identificar as demandas públicas, tais como reuniões, audiências públicas, e-mails, chats, fóruns, consultas públicas on-line etc.

Eixo5:Indicadoresdeimpactossociais. Refere-seacritériosquedeterminam os setores que se beneficiarão mais ou menos de certas políticas, considerandose que a complexa estratificação social da sociedade contemporânea dificulta sua identificação. É provável que certos grupos sejam privilegiados e outros preteridos, pelo menos em um mesmo período. Estão incluídas as seguintes categorias: 15. Bem-estar: os benefícios esperados de uma determinada política em termos de conforto material, cuidados de necessidades básicas etc; 16 . Igualdade: resultados de uma determinada política em termos de justiça social e distribuição justa de benefícios; 17. Satisfação do usuário: avaliada através de pesquisas, pesquisas ou feedback espontâneo.

Eixo 6: indicadores de impactos econômicos. Refere-se a expectativas de impactos das políticas de sustentabilidade ambiental para o desenvolvimento 
econômico, considerando-se que essas informações tendem a ser focalizadas de forma simplificada pelos governos, que temem suscitar controvérsias em torno de riscos e ameaças. Estão incluídas as seguintes categorias: 18. Eficácia: correspondência entre metas e resultados obtidos sob uma política de atendimento às necessidades dos diversos públicos; 19. Eficácia: mudanças reais ou impacto sobre as condições anteriores que foram o foco da política implementada. 20. Relação entre custo e efetividade: razões sobre o motivo pelo qual uma política foi escolhida, entre outras alternativas.

Os dados foram coletados de 02.01.2014 a 31.12.2014 apenas uma vez para cada portal, e a informação disponível foi nomeada em uma simples escala de pontos, em relação à sua profundidade e amplitude para cada uma das 20 categorias de análise de conteúdo. Usamos '1' para marcar a presença de qualquer informação correspondente em cada categoria e '0' para marcar a ausência de informações correspondentes. Assim, uma política pública apresentada com informações correspondentes ao total das 20 categorias receberia 20 pontos. O número de pontos efetivamente obtidos na avaliação de informações sobre cada política, quando considerado em relação ao máximo de 20 pontos, proporcionou um número percentual, indicando a abrangência das informações sobre políticas ambientais veiculadas pelos websites incluídos no estudo. Esse número, que se aplica a cada página web/unidade de análise e pode ser somado em toda a amostra e dividido pelo número total de páginas web/unidades de análise $(n=284)$ a fim de gerar uma média de desempenho dos portais web analisados em cada região geográfica e em todo o país, foi denominado Índice de Qualidade da Informação (IQI).

Para classificar o conteúdo das unidades deanálise dentro das 20 categorias formuladas, foram adotados, conforme as prescrições metodológicas usuais de análise de conteúdo, os critérios de classificação entre categorias mutuamente exclusivas e de constante interpretação da validade, homogeneidade e exaustividade de cada categoria (Fonseca Junior, 2006; Krippendorff, 1980).

Coleta e análise de dados para classificação nas categorias de análise foram realizadas por meio da aplicação de planilhas eletrônicas com o suporte de quatro estudantes de graduação em comunicação, das quais duas usufruíram bolsas do Programa Institucional de Bolsas de Iniciação Científica (Pibic) do Conselho Nacional de Desenvolvimento Científico e Tecnológico (CNPq) e duas receberam bolsas de Treinamento Técnico da Fapesp³. De forma geral, cada planilha referente a uma unidade federativa foi preenchida por uma bolsista

3 Os dados foram coletados e analisados com o suporte das estudantes de graduação Amanda Melo Lima, Carolina Ito Messias, Marina Goulart Dorigo e Nathalie Portela Tordin, às quais agradecemos pelo empenho. 
e revisada por outra bolsista. Havendo discordância entre as bolsistas sobre a classificação inicial, a decisão final de classificação foi avaliada por uma terceira bolsista, sob a supervisão do pesquisador responsável, que eventualmente autorizou correções e ajustes a fim a aumentar o índice de confiabilidade entre codificadores, que, no entanto, não pôde ser calculado com precisão dentro dos limites do desenho de pesquisa (LOVEJOY et al., 2016).

\section{Resultados e discussão}

A análise de 284 páginas web acessadas no ano de 2014 revelou a existência de valores que variaram de 14\% a 47\% das informações necessárias para uma caracterização completa de uma política ambiental, conforme estabelecido pelos pressupostos teóricos e metodológicos desta pesquisa. Em média, 32\% das informações necessárias foram encontradas.

Para facilitar a interpretação dos resultados, os 26 Estados brasileiros e o Distrito Federal foram agrupados nas cinco macrorregiões existentes, divisão política criada devido a níveis similares de desenvolvimento econômico e social, servindo a integração de seus componentes (Estados) para fins de design e implementação de políticas em áreas como educação, saúde, ciência e tecnologia e meio ambiente.

O Gráfico 1 exibe os Índices de Qualidade da Informação, expressos em termos de porcentagens de informações encontradas em websites de secretarias de meio ambiente das unidades federativas de cada macrorregião brasileira e do Ministério do Meio Ambiente. Nenhum dos grupos atingiu um índice superior a 50\%, o que significa que nenhum deles foi capaz de disseminar mais da metade das informações necessárias para uma caracterização completa de uma política ambiental, conforme estabelecido pelos pressupostos teóricos e metodológicos da pesquisa. Esse resultado pode ser interpretado no marco da lei brasileira sobre direito à informação (lei federal 12.527/2011). Devido à sua implementação relativamente recente (2012), pode não ter gerado ainda os resultados esperados em termos de transparência proativa on-line. Esse desempenho também pode ser influenciado pela falta de diretrizes, padrões ou políticas de transparência proativa, além de cultura política que nem sempre favorece a abertura e a prestação de contas (Rothberg, Napolitano \& Resende, 2013; Damatta, 2011). 
Gráfico 1. Percentuais de informação observados nos portais web das secretarias de meio ambiente dos 26 Estados das cinco macrorregiões brasileiras e do Ministério do Meio Ambiente

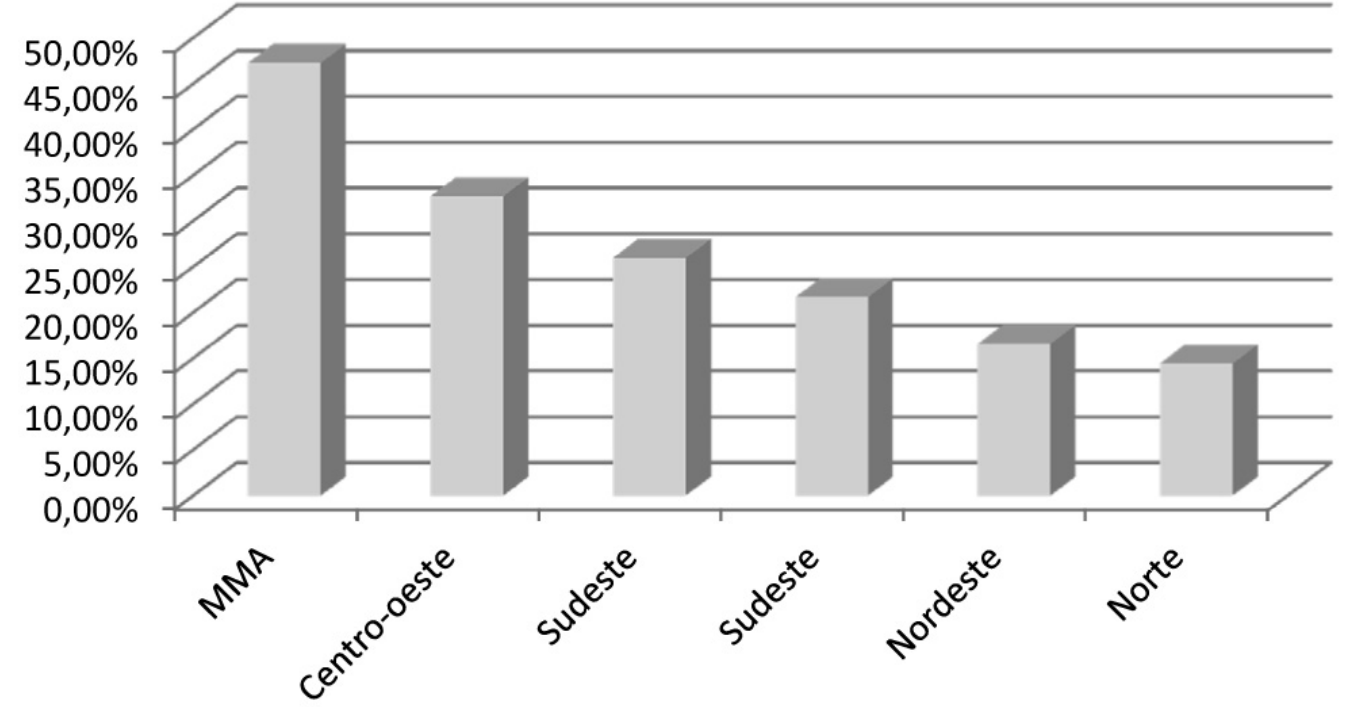

Fonte: elaboração própria

Deacordo como Gráfico 1, o portal do Ministério do Meio Ambiente obteve o melhor desempenho entre os websites incluídos no estudo, exibindo quase a metade $(47,26 \%)$ das informações consideradas necessárias sob os pressupostos teóricos e metodológicos da pesquisa. Foi seguido pelas macrorregiões CentroOeste, que apresentou um Índice de Qualidade da Informação de 32,70\%; Sul (25,97\%); Sudeste (21,67\%); Nordeste (16,57\%); e Norte (14,41\%).

O maior desempenho do website do Ministério do Meio Ambiente pode ser explicado como uma consequência provável do papel decisivo que ele desempenha na República brasileira. Muitas políticas, particularmente aquelas que implicam deveres legais de fiscalização da exploração de recursos naturais e licenciamento ambiental, são realizadas por órgãos federais, como Ibama (Instituto Brasileiro do Meio Ambiente e dos Recursos Naturais Renováveis) e ANA (Agência Nacional de Águas). Os atores estatais, privados e da sociedade civil nos 26 Estados, Distrito Federal e 5.570 municípios devem estar sintonizados em rede com o governo federal, ou correm o risco de não receber financiamento para uma variedade de programas de políticas que são projetados no nível federal e atingem o nível municipal por meio de transferências de recursos financeiros. O Ministério do Meio Ambiente parece estar assumindo a responsabilidade de liderar essa configuração federal, pelo menos no que se refere à divulgação de informações sobre a implementação de políticas. 
O Centro-Oeste apresentou o segundo desempenho, o que poderia ser explicado por sua posição como polo mais desenvolvido de empresas do agronegócio, legalmente sujeito a políticas de licenciamento ambiental (Parré \& Guilhoto, 2001). O Centro-Oeste foi em 2014 a macrorregião mais produtiva na produção de grãos, respondendo por quase 84 milhões de toneladas. Seu Estado mais produtivo (Mato Grosso) representou $24 \%$ da produção nacional de grãos. Com os outros dois Estados do Centro-Oeste (Goiás e Mato Grosso do Sul), a produção da macrorregião foi equivalente a 40,6\% da produção nacional em 2014 (CONAB, 2015). Vale ressaltar que o Brasil tem sido colocado consistentemente entre os cinco maiores produtores mundiais de grãos (USDA, 2011).

A macrorregião Sul apresentou o terceiro melhor desempenho na transparência proativa on-line, seguida pelas macrorregiões Sudeste, Nordeste e Norte. Esse resultado poderia ser explicado com a mesma linha de interpretação, já que o Sul está situado após o Centro-Oeste no ranking nacional de produção de grãos, com seus dois maiores produtores (Paraná e Rio Grande do Sul) respondendo por 34\% da produção nacional. A macrorregião Nordeste responde por $9 \%$, e o Norte, por $4 \%$.

Em síntese, observa-se a correspondência relativa entre o desempenho das macrorregiões brasileiras na transparência proativa on-line e seu desempenho no agronegócio, conforme indica o Gráfico 2.

Gráfico 2. Correspondência entre o desempenho das cinco macrorregiões brasileiras na transparência proativa on-line, indicada pelo Índice de Qualidade da Informação, e seu desempenho no agronegócio, avaliado pela sua produção de grãos em 2014

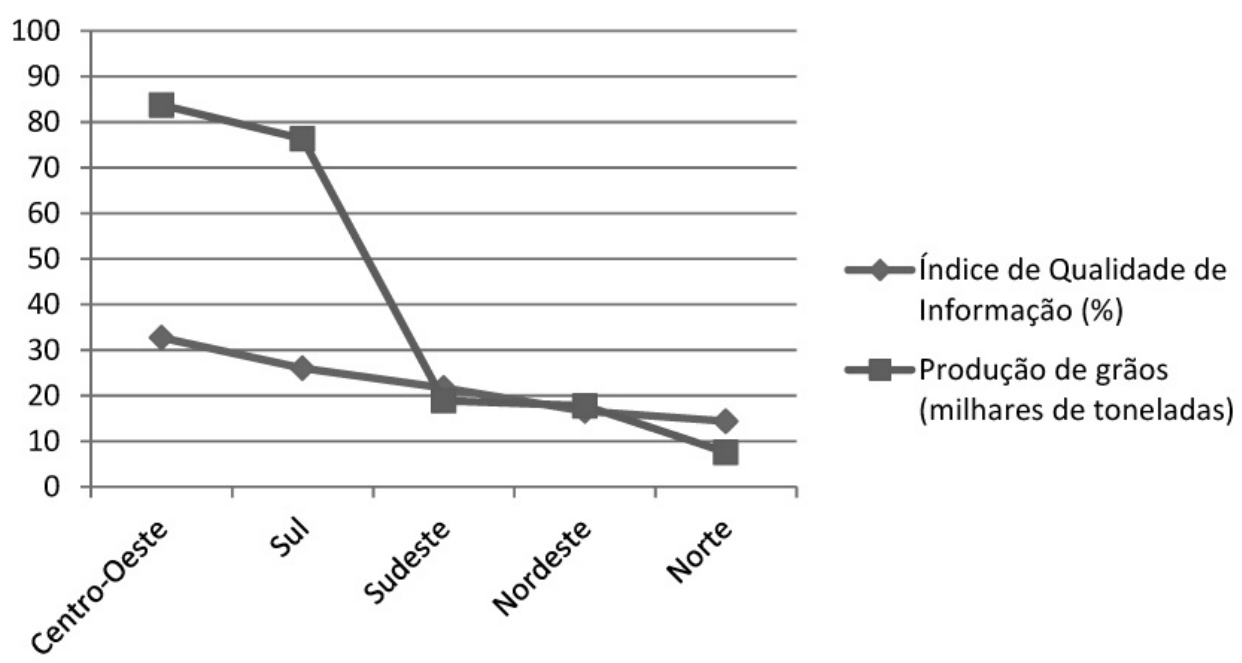

Fonte: elaboração própria 
O Gráfico 2 sugere uma hipótese a ser explorada por estudos futuros: quanto mais desenvolvido for um agronegócio de macrorregião em termos de produção líquida de grãos, maior será o desempenho da macrorregião na transparência proativa on-line, avaliada através do Índice de Qualidade da Informação.

A hipótese se coloca porque à medida que as políticas ambientais são em parte concebidas para minimizar os efeitos do agronegócio em termos de poluição da água, contaminação do solo e desmatamento, a sociedade civil poderia estar exigindo informações para exercer pressão sobre as secretarias de governo, exigindo que desempenhem suas funções reguladoras. 0 argumento poderia ser estendido para incluir o atendimento das necessidades de informação das empresas do agronegócio, que podem esperar que a visibilidade dos regulamentos ambientais que afetam suas operações seja tão amplamente disponível quanto possível, não apenas para o acesso de qualquer pessoa dentro da cadeia de negócios, mas também para fins de prestação de contas públicas sobre os investimentos que supostamente fizeram para cumprir o quadro legal. A divulgação on-line proativa poderia ser uma resposta a isso, permitindo à sociedade examinar as políticas públicas e responsabilizar o poder público pela sua correta implementação.

Naturalmente, o conjunto complexo de fatores potencialmente determinantes de melhores portais web de governo não pode ser reduzido a um único fator de influência, particularmente um que guarda relações entre governo e sociedade para o qual seria muito difícil produzir evidências. No entanto, a correspondência entre transparência de governo e desenvolvimento econômico - que considera a existência de meios que facilitam a responsabilização de governos como incentivo ao aprofundamento da governança democrática, que por sua vez tende a favorecer o desempenho da economia - tem sido explorada na literatura (Andrews, 2012; Grafton \& Knowles, 2004; Gundelach, 2015; Mohan \& Mohan, 2002; Putnam, 1993, 1995, 2000), trazendo uma hipótese a ser verificada por estudos futuros.

O Gráfico 3 mostra a prevalência de informações sobre políticas públicas por categorias de análise de conteúdo encontradas em portais web de secretarias de meio ambiente. 
Gráfico 3. Percentuais de informações sobre políticas públicas por categorias de análise de conteúdo encontradas em portais web de secretarias de meio ambiente

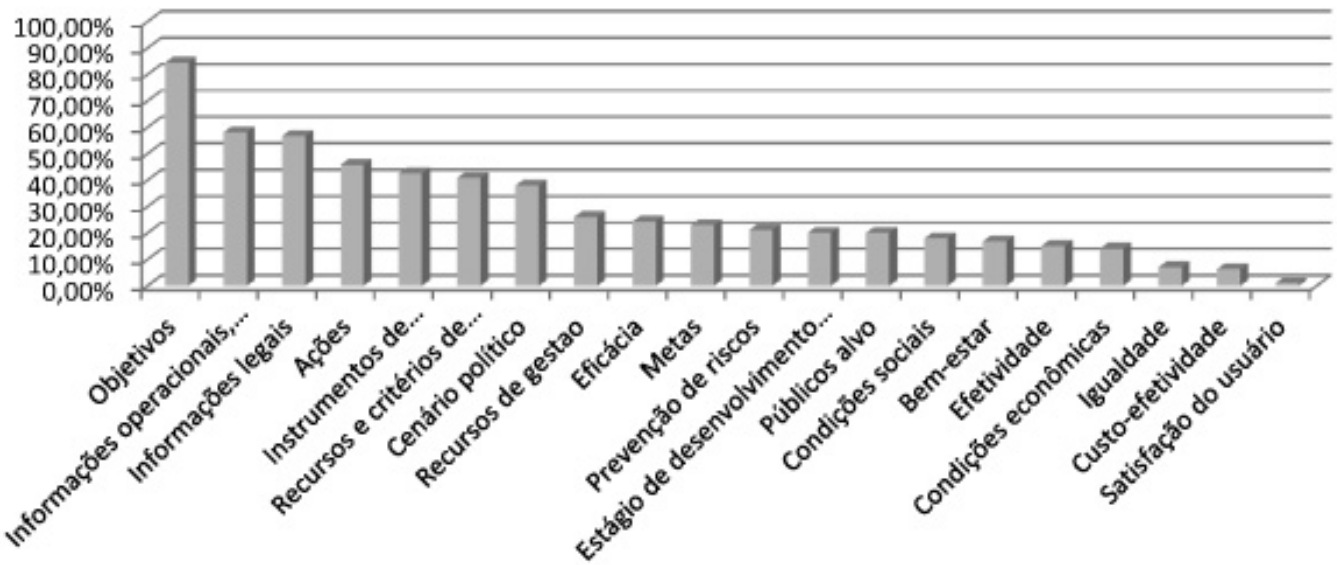

Fonte: elaboração própria

O Gráfico 3 exibe a proporção, em termos de números percentuais, de páginas web em relação à toda a amostra que apresentou informações classificadas em cada categoria. Encontramos informações classificadas na categoria"objetivos"em 240 das 284 páginas web analisadas (84,5\%), o que a torna a única categoria de informação encontrada em mais de dois terços das páginas analisadas. Isso sugere que os governos têm estado dispostos a se apresentar como autoridades que sabem o que estão fazendo, o que poderia ser uma resposta às expectativas mais básicas levantadas pelas leis de direitoà informação entre os cidadãos em relação à transparência e responsabilidade do governo.

Depois de "objetivos", podemos agrupar as 19 categorias em quatro faixas separadas, cada uma com categorizações com resultado similar:

Faixa "a": Informações classificadas em "informações operacionais, parcerias e convênios" foram encontradas em 165 das 284 páginas web analisadas (58,10\%), e "informações legais", em 161 (56,70\%). Isso sugere que os governos têm permanecido predominantemente preocupados em fornecer informações sobre como se beneficiar de uma política e com o quadro legal de suas políticas. Tais categorias de informação on-line sobre políticas de sustentabilidade servem não só a cidadãos que podem estar interessados, por exemplo, em saber como reclamar da qualidade dos recursos hídricos por eles contratados, mas também como se movem no quadro mais amplo da política federal as autoridades públicas localizadas em níveis mais próximos de gestão, como municípios. Assim, os portais web de governos estaduais poderiam estar explorando a comunicação on-line para dirigir uma mensagem aos prefeitos sobre como podem ser estratégicas as alianças e parcerias entre eles para dinamizar as políticas da área. 
Faixa "b": informações sobre "ações" foram encontradas em 130 das 284 páginas analisadas (45,80\%); sobre "instrumentos de relacionamento", em 121 páginas web (42,60\%); "recursos e critérios de eficácia", em 116 (40,85\%); "cenário político", em 108 (38\%). Isso sugere que os governos têm priorizado comparativamente a divulgação de informações sobre exatamente o que fazem em termos das operações mais visíveis decorrentes de suas prioridades de ação, incluindo o arranjo das forças políticas responsáveis por suas realizações, e também cobrindo aspectos relacionados à maneira como eles vêm a decidir sobre qual política específica deve ser implementada, e como a política está sendo gerenciada, a fim de alcançar resultados alegadamente melhores.

Faixa "c": Informações sobre "recursos de gestão" foram encontradas em 74 das 284 páginas web analisadas (26\%); “eficácia”, em 69 (24,30\%); “metas”, em 65 (22,90\%); "prevenção de riscos", em 60 (21,10\%); "estágio de desenvolvimento científico e tecnológico" e "públicos alvo", em 57 (20,10\%); "condições sociais", em 51 (18\%); "bem-estar", em 48 (16,90\%);"efetividade", em 43 (15,15\%); e "condições econômicas", em 40 (14,10\%). Isto sugere que a informação sobre aspectos fundamentais do contexto de formulação e implementação das políticas da área tem recebido relativamente menos atenção dos gestores dos portais web. Com base apenas no que podem encontrar em portais web oficiais, os cidadãos raramente poderiam formar uma perspectiva sobre as razões subjacentes às escolhas políticas, relacionadas com contextos sociais, econômicos e sobre quais públicos foram beneficiados. O conteúdo on-line não seria suficiente para fomentar a compreensão dos critérios específicos de implementação de políticas, e nem para facilitar a percepção do que teria sido feito por um governo para maximizar o impacto de uma dada política, ou para subsidiar a compreensão de como uma política se fundamenta no conhecimento científico ou está apta ao gerenciamento de riscos ambientais.

Faixa "d": Informações sobre "igualdade"foram encontradas em 20 das 284 páginas web analisadas (7\%); "custo-efetividade", em 18 (6,30\%); "satisfação do usuário", em 3 (1\%). Isto sugere que os cidadãos podem ter sido impedidos de descobrir que uma política pode beneficiar mais do que outros, e de encontrar possíveis justificativas para isso. Os cidadãos também poderiam ter sido excluídos do conhecimento sobre por que uma política particular foi escolhida entre outras alternativas, de acordo com escolhas possivelmente explicadas por razões legítimas, que, no entanto, permaneceram escondidas. Finalmente, os governos não mostraram praticamente qualquer interesse em divulgar informações sobre o que os cidadãos têm dito sobre as políticas ambientais que podem beneficiá-los, ou mesmo se os governos têm se preocupado em ouvir suas opiniões. 


\section{Conclusões}

Este artigo apresentou resultados de pesquisa sobre o papel da informação política sobre sustentabilidade ambiental para o fortalecimento da cidadania no Brasil, considerada em sua dimensão de exercício do direito à informação.

Os resultados indicam que a informação disponível nos websites do governo pode ser considerada insuficiente para caracterizar de forma satisfatória as políticas públicas da área, e apontam a necessidade de aperfeiçoamento da disponibilidade de informação política sobre sustentabilidade no Brasil. No percurso de ampliação do direito à informação, uma referência central é dada pelas categorias apontadas por estudos como relevantes para a cidadania neste âmbito (Darbishire, 2010; OAS, 2012).

Sugerimos que o quadro de avaliação aqui utilizado, propondo uma lista de verificação de 20 critérios para a comunicação abrangente de políticas, constitua critérios de gestão da comunicação, para que as secretarias ambientais em todo o Brasil busquem efetivamente fornecer informações necessárias ao engajamento democrático.

Os resultados indicaram, sobretudo, a correspondência entre o nível de desenvolvimento do agronegócio (medido pela produção de grãos) e o desempenho da transparência proativa on-line (avaliada pelo Índice de Qualidade da Informação), sugerindo uma hipótese a ser explorada por pesquisas adicionais, de que quanto mais desenvolvido for o agronegócio de uma macrorregião, maior a transparência online de governo daquela macrorregião.

Se ratificado por estudos futuros, esse resultado pode indicar que a política digital pode estar contribuindo para a promoção da sustentabilidade ambiental no Brasil, no sentido de que os portais de governo responderiam às necessidades de informação dos setores sociais dispostos a monitorar políticas de sustentabilidade em regiões onde ações políticas tornam-se particularmente importantes devido ao desenvolvimento do agronegócio. Além disso, a informação on-line e a transparência proativa permitiriam que a sociedade responsabilizasse o poder público por suas escolhas políticas, através de um monitoramento ativo que tem sido visto pelos estudos de governança democrática como vitais para se alcançar a sustentabilidade (Dokeniya, 2013, Bevir, 2009, 2010; Gundelach, 2015). 


\section{Referências}

$A B E R S, R . N ., K E C K, M$. E. Practical authority: agency and institutional change in Brazilian water politics. Oxford: Oxford University Press, 2013.

ANDREWS, R. Social capital and public service performance: a review of the evidence.

Public Policy and Administration, v. 27, n. 1, p. 49-67, 2012.

ARRETCHE, M. Tendências no estudo sobre avaliação. In: RICO, E. M. (org.) Avaliação de políticas sociais: uma questão em debate. São Paulo: Cortez, 1998.

BATISTA, C. L. Informação pública: controle, segredo e direito de acesso. Intexto, n. 26, p. 204-222, 2012.

BECK, U. Risk society: towards a new modernity. London: Sage, 1992.

BELLEN, H. M. Indicadores de sustentabilidade: uma análise comparativa. Rio de Janeiro: FGV, 2006.

BEVIR, M. Key concepts in governance. London: Sage, 2009.

BEVIR, M. Democratic governance. Princeton: Princeton University, 2010.

BRASIL. Lei no 12.527, de 18 de novembro de 2011. Regula o acesso a informações. Brasília, DF: 2011.

BRASIL. Decreto n 7.724, de 16 de maio de 2012. Regulamenta a Lei no 12.527, de 18 de novembro de 2011, que dispõe sobre o acesso a informações. Brasília, DF: 2012.

BREWER, G. A., NEUBAUER, B. J., GEISELHART, K. Designing and implementing e-government systems: critical implications for public administration and Democracy. Administration \& Society, v. 38, n. 4, p. 472-499, 2006.

COLEMAN, S., BLUMLER, J. G. The internet and democratic citizenship: theory, practice and policy. Cambridge, Cambridge University Press, 2009.

CONAB. Companhia Nacional de Abastecimento. Monitoramento Agrícola. Safra 2014/15. Brasília, DF: Ministério da Agricultura, Pecuária e Abastecimento, 2015.

COSTA, F. L.; CASTANHAR, J. C. Avaliação de programas públicos: desafios conceituais e metodológicos. Revista de Administração Pública, v. 37, n. 5, p. 962-969, 2003.

DAHLBERG, L. Re-constructing digital democracy: an outline of four 'positions'. New Media \& Society, v. 13, n. 6, p. 855-872, 2011.

DAMATTA, R. Diagnóstico sobre valores, conhecimento e cultura de acesso à informação pública no Poder Executivo federal brasileiro. Brasília, 
Controladoria-Geral da União, 2011.30 p.

DARBISHIRE, H. Proactive transparency: the future of the right to information? Washington, DC: World Bank Institute, 2010.

DOKENIYA, A. Implementing right to information. Prem Notes 5. Special Series on Governance \& Public Sector Management. Washington: World Bank, 2013.

GRAFTON, R. Q., KNOWLES, S. Social capital and national environmental performance: a cross-sectional analysis. The Journal of Environment Development, v. 13, n. 4, p. 336-370, 2004.

GUNDELACH, B. Economic development and civic engagement in Latin America: a comparative study. Nonprofit and Voluntary Sector Quarterly, p. 1-23, 2015.

FONSECA JUNIOR, W. C. Análise de conteúdo. In: BARROS, A.; DUARTE, J. Métodos e técnicas de pesquisa em comunicação. São Paulo: Atlas, 2006. p. 280-304.

HENRY, G. T. How modern democracies are shaping evaluation and the emerging challenges for evaluation. American Journal of Evaluation, v. 22, n. 3, p. 419429, 2001.

KHAN, G. F. The Government 2.0 utilization model and implementation scenarios. Information Development, v. 31, n. 2, p. 135-149, 2015.

KRIPPENDORFF, K. Content analysis: an introduction to its methodology. Beverly Hills, CA: Sage, 1980.

LATOUR, B. Politics of nature: how to bring the sciences into democracy. Cambridge, MA: Harvard University Press, 2004.

LOVEJOY, J., WATSON, B. R, LACY, S.; RIFFE, D. Three decades of reliability in communication content analyses: reporting of reliability statistics and coefficient levels in three top journals. Journalism \& Mass Communication Quarterly, v. 93, n. 4, p. 1135-1159, 2016.

MOHAN, G., MOHAN, J. Placing social capital. Progress in Human Geography, v. 26, n. 2, p, 191-210, 2002.

OAS. Organization of American States. Model inter-American law on access to public information and its implementation guidelines. Washington: Department of International Law, Secretariat for Legal Affairs, Organization of American States, 2012.

O'DONNELL, G. A. Horizontal accountability in new democracies. Journal of Democracy, v. 9, n. 3, 112-126, 1998.

PARRÉ, J. L.; GUILHOTO, J. L. M. A desconcentração regional do agronegócio brasileiro. Revista Brasileira de Economia, v. 55, n. 2, p. 223-251, 2001. 
PUTNAM, R. Making democracy work: civic traditions in modern Italy. Princeton: Princeton University Press, 1993.

Bowling alone: America's declining social capital. Journal of Democracy, v. 6, n. 1, p. 65-78, 1995.

Bowling alone: the collapse and revival of American community. New York: Simon and Schuster, 2000.

ROTHBERG, D., NAPOLITANO, C. J., RESENDE, L.P. Estado e burocracia: limites de aplicação da Lei de Acesso a Informações no Brasil. Fronteira Estudos Midiáticos, v. 15, n. 2, p. 108-117, 2013.

TREVISAN, A. P.; BELLEN, H. M. Avaliação de políticas públicas: uma revisão teórica de um campo em construção. RAP - Revista de Administração Pública, v. 42, n. 3, p. 529-50, 2008.

USDA. United States of America Department of Agriculture. Production, Supply and Distribution. Washington, DC: Foreign Agricultural Service, 2011.

WEISS, C. H. Have we learned anything new about the use of evaluation? American Journal of Evaluation, v. 19, n. 1, p. 21-34, 1998.

UNECE. United Nations Economic Commission for Europe. Aarhus Convention on access to information, public participation in decision-making and access to justice in environmental matters. Aarhus, Denmark, 1998.

Dados do autor:

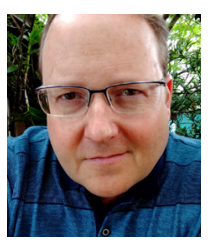

Danilo Rothberg | danroth@uol.com.br

Universidade Estadual Paulista - UNESP

Doutor em Sociologia e Livre-docente em Sociologia da Comunicação pela Unesp (Universidade Estadual

Paulista). Coordenador do Programa de Pós-Graduação em Comunicação da Faculdade de Arquitetura,

Artes e Comunicação da Unesp.

Universidade Estadual Paulista (Unesp)

Endereço do autor:

Av. Eng. Luiz Edmundo Carrijo Coube, n 14-01 - Vargem Limpa

17033-360 - Bauru (SP) - Brasil 